\title{
CORRIGENDA
}

\section{Non-invasive prenatal testing for aneuploidy and beyond: challenges of responsible innovation in prenatal screening}

Wybo Dondorp, Guido de Wert, Yvonne Bombard, Diana W Bianchi, Carsten Bergmann, Pascal Borry, Lyn S Chitty, Florence Fellmann, Francesca Forzano, Alison Hall, Lidewij Henneman, Heidi C Howard, Anneke Lucassen, Kelly Ormond, Borut Peterlin, Dragica Radojkovic, Wolf Rogowski, Maria Soller, Aad Tibben, Lisbeth Tranebjærg, Carla G van El and Martina C Cornel on behalf of the European Society of Human Genetics (ESHG) and the American Society of Human Genetics (ASHG)

European Journal of Human Genetics (2015) 23, 1592; doi:10.1038/ejhg.2015.109

Correction to: European Journal of Human Genetics (2015) 23, 1438-1450; doi:10.1038/ejhg.2015.57; published online 18 March 2015

An error was made when presenting results of the CARE study by Bianchi et al.

The sentence: 'They found a sensitivity of $100 \%$ (for all three trisomies) (95\% confidence interval (CI): 99.8-100), at a specificity of 99.7 and $99.8 \%$ for trisomies 21 and 18 , respectively' should have read: 'While detecting all eight cases of the three trisomies, this study found a specificity of 99.7 for trisomy 21 (95\% CI: 99.3-99.9) and 99.8 for trisomy 18 (95\% CI: 99.6-100).

The authors would like to apologise for their error.

\section{Microsatellite data show recent demographic expansions in sedentary but not in nomadic human populations in Africa and Eurasia}

Carla Aime, Paul Verdu, Laure Ségurel, Begoña Martinez-Cruz, Tatyana Hegay, Evelyne Heyer and Frédéric Austerlitz

European Journal of Human Genetics (2015) 23, 1592; doi:10.1038/ejhg.2014.276

Correction to: European Journal of Human Genetics (2014) 22, 1201-1207; doi:10.1038/ejhg.2014.2; published online 12 February 2014

Since the publication of this article the authors have found that they had listed reference 37 incorrectly. The correct reference is shown here:

Martinez-Cruz B, Vitalis R, Segurel L et al: In the heartland of Eurasia: the multilocus genetic landscape of Central Asian populations. Eur J Hum Genet 2011; 19: 216-223.
In Table S1, the correct references for the genotypes of the CentralAsian populations were 35,37 and not 37,38 as indicated, except for the five following populations that were newly genotyped for this study: Tajiks (Boukhara), Tajiks (Muchaus), Kyrgyz (Bichkek), Kyrgyz (At-Bashy) and Turkmen (Urgench).

The authors would like to apologise for their errors. 